\title{
CHRONIC DIARRHEA;
}

\section{LARGE GUT CAUSES}

\author{
${ }^{*}$ DR. RAFI UD DIN \\ Lahore. \\ DR. MANZAR ZAKARIA \\ Lahore
DR. MUJEEB-UR-REHMAN ABID BUTT
Lahore.

Article received on:

$14 / 06 / 2008$

Accepted for publication: $01 / 09 / 2008$

\begin{abstract}
Objective: To determine the frequency of large bowel causes of chronic diarrhea in adult Pakistani patients. Study Design: Cross sectional study. Setting: Medical unit 1 at Combined Military Hospital Lahore, Pakistan. Duration: Six months (from 01-112007 to 30-4-2008). Subjects and Methods: Fifty adult patients with chronic diarrhea, irrespective of their gender were selected by non probability convenient sampling. Patients already diagnosed with diseases known to cause diarrhea and those with toxic mega colon were excluded from the study. All patients were subjected to fiberoptic colonoscopy and findings were recorded. Biopsies were taken from suspected lesions or from normal looking mucosa. Diagnosis was made with colonoscopic and histopathologic findings. Results: Thirty two (64\%) patients had abnormal findings visible on colonoscopy. Histopathology was normal in 18 (36\%). Twenty (40\%) patients had ulcerative colitis, seventeen (34\%) had IBS, five (10\%) had CA colon and three (6\%) patients had crohn's disease. Other diagnoses included non specific colitis, tubulovillous adenoma and infection. Twenty three out of 24 patients (95\%) who had blood in stools had a visible abnormality on colonoscopy whereas colonoscopy was positive in only $33 \%$ of patients who did not have blood in stools. Conclusion: Most causes of large gut chronic diarrhea can be identified by colonoscopy and biopsy. Colonoscopy has a very high yield in chronic diarrhea and should be recommended for its work up. Its yield is even higher in patients with bloody diarrhea.
\end{abstract}

Key words: $\quad$ Colonoscopy, Diarrhea, Colitis.

\section{INTRODUCTION}

Chronic diarrhea is defined as a decrease in fecal consistency lasting for four or more weeks 1. Prevalence of chronic diarrhea varies in different populations but a reasonable approximation is that it affects about $5 \%$ of the population.2-4 One estimate based upon limited data suggests that chronic diarrhea costs more than $\$ 350,000,000$ annually from work-loss in USA alone5. A myriad of disorders are associated with chronic diarrhea. The prevalence of specific disorders varies based upon the practice setting ${ }^{1}$.

Colonoscopy with biopsy is an important part of diagnostic work up in cases of chronic diarrhea especially to rule out structural and occult inflammatory disease $^{6}$. Studies have shown that a significant proportion of causes of chronic diarrhea lie in the large bowel which can be diagnosed by endoscopy and 
biopsy of the lesions ${ }^{7,8}$. There has been a considerable debate as to whether sigmoidoscopy or colonoscopy should be the initial procedure of choice. Colonoscopy is useful even in cases which can be diagnosed by sigmoidoscopy and it provides the added advantage of measuring the severity and extent of disease like ulcerative colitis ${ }^{9}$.

Chronic diarrhea, while well studied in pediatric age group, has received little attention as a subject of research in adult population in Pakistan. Although no statistical data are available, chronic diarrhea is frequently seen in clinical practice in our country. It causes significant morbidity leading to work loss and may be a symptom of sinister diseases like colonic malignancy ${ }^{10}$. Hence there is need to identify the common causes of chronic diarrhea in our adult population so that measures could be devised to minimize preventable causes. Purpose of the current study was to determine the frequency of large bowel causes of chronic diarrhea and hence to evaluate the usefulness of colonoscopy in the diagnosis of chronic diarrhea in our set up.

\section{PATIENTS AND METHODS}

The study was carried out in medical units I at Combined Military Hospital Lahore, Pakistan which is a 800 bed tertiary care hospital. Both indoor as well as outdoor patients were enrolled. Fifty patients with chronic diarrhea were studied. Duration of study was 6 months starting from 1 Nov 2007 to 30 April 2008.

\section{DATA COLLECTION PROCEDURE}

It was a cross sectional study for frequency. Fifty, previously undiagnosed adult patients with diarrhea of 4 weeks duration or more, both males and females, at Combined Military Hospital Lahore were included in this study and categorised them with respect to age (under 20, 20 to 40 and above 40). Patients already diagnosed with small gut diarrhea, patients with known diseases causing chronic diarrhea and those with contraindications to colonoscopy like suspected toxic mega colon were excluded.

Detailed history was taken and physical examination was carried out. Following investigations were done in all patients,

1. Full blood counts with ESR

2. Stool analysis for ova and cysts

3. Fecal leukocytes

4. Fasting blood glucose levels

5. Serum albumin levels

6. Chest X-ray PA view

Following investigations were performed when indicated clinically in selected patients,

1. Serum levels of T4 and TSH - in patients with clinical suspicion of hyperthyroidism

2. 24 hour stool for fecal fat measurement - in patients suspected to have malabsorption

3. Stool for occult blood - in all patients who did not have visible blood in diarrhea

4. d-xylose test

5. Upper Gastrointestinal Endoscopy and Barium Meal Study.

After prerequisite preparation patients were subjected to fibre-optic colonoscopy and findings were recorded. Biopsies were taken from suspected lesions or from normal looking mucosa if no lesions were seen. Diagnosis was made on the basis of colonoscopic and histopathologic findings.

\section{DATA ANALYSIS}

All the data collected was entered in SPSS version 11 and analyzed through its statistical package. 
Descriptive statistics (frequency distribution and percentages) were calculated for qualitative data like gender, abdominal pain, blood in stools and different diagnoses. Mean and standard deviation were calculated for quantitative data like age, hemoglobin and BMI. No inferential test was applied as it was a descriptive study.

\section{RESULTS}

Study population included 50 patients, 12 women $(24 \%)$ and 38 men $(76 \%)$, with diarrhea of at least 4 weeks duration. There were no complications of the procedure. Mean age of the patients was $39.08 \pm$ 12.71 years $(95 \% \mathrm{Cl} 27-51)$. Women and men were of comparable ages (mean age for men was $39 \mathrm{yrs}$ and that of women was $42 \mathrm{yrs}$ ). Mean body mass index (BMI) was $23.03 \pm 1.64 \mathrm{~kg} / \mathrm{m} 2$. Women had lower mean BMI $(21.5 \mathrm{~kg} / \mathrm{m} 2)$ than men $(23.4 \mathrm{~kg} / \mathrm{m} 2)$ and this difference is statistically significant as $p$-value is 0.003 . The mean BMI is statistically insignificant with respect to age categories with p-value 0.298 .

Presence of symptoms associated with chronic diarrhea was also recorded. Twenty four (48\%) patients had a history of passing blood in stools on most occasions during the course of illness. Chronic diarrhea was associated with history of abdominal pain in $19(38 \%)$ patients whereas history of significant weight loss was present in only $8(16 \%)$ patients. Blood in stools is not statistically associated with either abdominal pain or weight loss but abdominal pain is statistically associated with weight loss with p-value 0.000 . Table-I compares the frequency of associated symptoms.

\begin{tabular}{|l|c|c|}
\hline \multicolumn{3}{|c|}{ Table-I. Frequency of Associated Symptoms } \\
\hline Symptom & No. of Pts. & $\%$ age \\
\hline Abdominal pain & 19 & $38 \%$ \\
\hline Blood in stools & 24 & $48 \%$ \\
\hline Weight loss & 08 & $16 \%$ \\
\hline
\end{tabular}

\begin{tabular}{|l|c|}
\hline \multicolumn{2}{|c|}{ Table-Il. Colonoscopic Findings } \\
\hline Diseases & No. Of Pts. \\
\hline Pancolitis & $9(18 \%)$ \\
\hline Left sided colitis & $6(12 \%)$ \\
\hline Proctitis & $5(10 \%)$ \\
\hline Proctosigmoiditis & $2(4 \%)$ \\
\hline Crohn's disease & $2(4 \%)$ \\
\hline Growth rectum \& sigmoid colon & $2(4 \%)$ \\
\hline Growth sigmoid colon & $1(2 \%)$ \\
\hline Rectal polyp & $1(2 \%)$ \\
\hline Proctocolitis & $1(2 \%)$ \\
\hline Growth descending colon & $2(4 \%)$ \\
\hline Polp ascending colon & $1(2 \%)$ \\
\hline Normal & $18(36 \%)$ \\
\hline
\end{tabular}

Colonoscopy showed abnormalities in 32 (64\%) patients. Only $1(2 \%)$ patient had visible lesions limited to parts of colon proximal to the splenic flexure. However $10(20 \%)$ patients (all with ulcerative colitis) had abnormalities in descending colon extending proximally into transverse colon. Most common finding was inflammation of the colon which was noted in 25 $(50 \%)$ while Pan colitis was seen in $9(18 \%)$ patients. Other colonoscopic findings are shown in Tab-II. Colonoscopy is highly associated with Blood in stools with $p$-value 0.008 .

Histopathologic examination was normal in 18 (36\%) patients while a specific histopathologic diagnosis was made in $32(64 \%)$ patients. Ulcerative colitis was the most common histopathologic diagnosis, found in 20 $(40 \%)$, colonic malignancy was seen in $5(10 \%)$ and crohn's disease was diagnosed in $3(6 \%)$ patients. Other less common diagnoses are shown in Tab-III. Colonoscopy and Histopathology are not statistically 
associated with either sex or age categories.

\begin{tabular}{|l|c|}
\hline \multicolumn{2}{|c|}{ Table-III. Histopathological Diagnoses } \\
\hline Diseases & No. of Patients (\%) \\
\hline Ulcerative colitis & $20(40 \%)$ \\
\hline Adenocarcinoma & $5(10 \%)$ \\
\hline Crohn's colitis & $3(6 \%)$ \\
\hline Non specific colitis & $2(4 \%)$ \\
\hline Tubulovillous adenoma & $2(4 \%)$ \\
\hline Normal & $18(36 \%)$ \\
\hline
\end{tabular}

Out of 18 patients who had normal histopathology, 17 $(34 \%)$ were diagnosed to have IBS and one patient had probable infection as diarrhea responded to antibiotics, though microbiological etiology could not be ascertained.

Out of 17 patients of IBS, 3 were women (6\%) and 14 were men $(28 \%)$. Mean age for women with IBS was $29 \mathrm{yrs}$ and that for men was 33 yrs. Bloody diarrhea was the most common symptom associated with an abnormality being found on colonoscopy. Twenty three out of 24 patients (95\%) who had blood in stools had a visible abnormality on colonoscopy whereas colonoscopy was positive in only $33 \%$ of patients who did not have blood in stools.

\section{DISCUSSION}

Most common causes of large gut chronic diarrhea in the study population are ulcerative colitis (40\%) and irritable bowel syndrome (34\%) though It is generally agreed that common causes of chronic diarrhea in the developing countries are bacterial, mycobacterial and parasitic infections ${ }^{6}$, however results of the present study tend to contradict with this statement.

A number of disorders are associated with chronic diarrhea and the distribution of different diseases varies according to the clinical setting ${ }^{1}$. Principal causes of diarrhea depend upon the socioeconomic status of the population. The infectious causes like Intestinal TB and amebiasis were not diagnosed in any patient in this study. This probably reflects the changing etiologic pattern of the problem. Use of antibiotics has become extremely common so that infections like amebiasis and giardiasis are commonly and effectively treated at an early stage without confirming the diagnosis. Tuberculosis is being diagnosed and effectively treated at an increasingly early stage because of better health facilities and availability of effective chemotherapeutic agents. This along with the availability of safe potable water and increasing literacy rate have probably contributed and brought down the share of infectious causes contributing towards chronic diarrhea.

Colonoscopy with biopsy provided the diagnosis in $64 \%$ of patients which proves the importance of this procedure as part of the work up in chronic diarrhea while Shah et $\mathrm{al}^{11}$ found that colonoscopy with biopsy yielded the diagnosis in $31 \%$ of their cases. In patients with history of blood in stools, the diagnostic yield of the procedure rose to $95 \%$. Although very few lesions were present proximal to the splenic flexure and most of the patients could be diagnosed with the help of a 60 $\mathrm{cm}$ sigmoidoscopy. Disease process often involved proximal parts of the colon in addition to rectum, sigmoid and descending colon in patients with ulcerative colitis. In these patients extent of the disease process could only be measured with colonoscopy. Hence a full colonoscopy is justified in chronic diarrhea especially if there is history of rectal bleeding though Fine $^{12}$ found that sigmoidoscopy detected the lesions and gave accurate diagnosis in $99.7 \%$ of cases and found it to be very efficient and cost effective. We didn't find a single case of microscopic colitis in patients with normal colonoscopy however studies showed that this type of colitis can only be diagnosed by histopathology of normal looking mucosa ${ }^{13,14}$. 
Out of eighteen normal colonoscopies in this study 17 ultimately diagnosed to have IBS while 1 had infective colitis. This is in accordance with Marshall ${ }^{15}$ who revealed that in a normal colonoscopy yield of blind biopsy is very low. While Lee et $\mathrm{al}^{16}$, Gineston et $\mathrm{al}^{17}$ and Thijs et $a^{18}$ have found that clinically important histopathological lesions can be diagnosed in normal colonoscopy. da Silva et $\mathrm{al}^{19}$ found that possible diagnostic clues can be obtained in $32.1 \%$ of patients having normal colonoscopy if biopsies are taken for histopathology but we could not find a single pathological diagnosis in normal macroscopic colonoscopies even on histopathology.

There has been considerable variation in diagnostic yield of colonoscopy in chronic diarrhea reported in different studies. Fine ${ }^{11}$ studied 809 patients of chronic non bloody diarrhea retrospectively. One hundred and twenty two (15\%) patients could be given a specific histopathologic diagnosis. Microscopic colitis was seen in $80(10 \%)$ patients, crohn's disease in $23(3 \%)$, ulcerative colitis in $5(0.6 \%)$. Six hundred and eighty seven $(85 \%)$ patients had normal histology. Out of these, $332(41 \%)$ had diseases associated with steatorrhea, 283 (35\%) had diarrhea due to non steatorrheic secretory or dysmotility processes (including IBS). The results of this study are markedly different from the present study. The major reason for this difference seems to be exclusion of patients with bloody diarrhea by Fine as patients with ulcerative colitis commonly present with bloody chronic diarrhea. Shah et a ${ }^{12}$ evaluated the usefulness of colonoscopy in 168 patients. A specific histological diagnosis was made in $52(31 \%)$ patients. The most common diagnoses were lymphocytic colitis 10(\%), Crohn's disease $9(\%)$, ulcerative colitis $7(\%)$, infectious colitis $6(\%)$ and collagenous colitis $3(\%)$. Non specific colitis was seen in $14(9 \%)$ patients and normal histology was found in $101(60 \%)$ patients. Fifty three patients (\%) in total were diagnosed to have IBS, almost similar number of cases in our study. This study has reported a relatively low diagnostic yield of colonoscopy compared to the present study. The reasons for these differences may be referral bias or variation in the population under study.

The most common diagnoses in the study by AlBayatti $^{7}$ in patients with chronic diarrhea were ulcerative colitis, celiac disease, microscopic colitis and functional diarrhea (IBS) in that order. He found that $56 \%$ of patients had causes of chronic diarrhea originating in the large gut which were diagnosed by colonoscopic biopsies and this makes the diagnostic yield similar to this study.

Another study carried out on 71 patients by Garg et al ${ }^{8}$ reported IBS in 32 patients (45\%) as the most common diagnosis. Ulcerative colitis was diagnosed in 18 $(25 \%), 5(7 \%)$ patients were diagnosed to have lymphocytic colitis, colorectal malignancy was seen in $3(4.2 \%)$ and colonic polyps also in $3(4.2 \%)$ patients. Seven $(9.8 \%)$ patients in the study had seronegative arthritis with chronic diarrhea and were found to have chronic inflammation of the colon on biopsy. The diagnostic yield of colonoscopy in the study turned out to be $>50 \%$. Results of the present study are closer to those of Garg et al which has shown a high yield of colonoscopy as well as frequency of different diagnoses.

Combined Military hospital Lahore is a tertiary care centre and receives referrals from all over the country especially patients belonging to the armed forces. Possibility of referral bias cannot be excluded. Patients reaching this hospital have usually been through preliminary investigations and some had even had colonoscopies previously. Many had already taken empirical courses of antibiotics and other treatment. All these factors may have been sources of bias.

The total number of patients was small and for this reason results of this study may not be a true reflection of the situation in general population and further cross sectional studies should be done 


\section{CONCLUSION}

Results of this study have shown a high diagnostic yield $(64 \%)$ of colonoscopy in cases of chronic diarrhea. The procedure is safe and has negligible risk of complications (there were no complications of the procedure in the present study). On the basis of these results, colonoscopy can be recommended as an essential part of investigations in chronic diarrhea. A history of blood in stools is an even stronger indication for the procedure as the probability of an abnormality being found in such patients is even higher (95\%).

Most patients (64\%) in this study had causes of chronic diarrhea residing in the large bowel. No infectious causes were identified. It disproves the popular belief that infections are amongst the leading causes of chronic diarrhea in developing nations ${ }^{6}$.

\section{REFERENCES}

1. Bonis PAL, LaMont JT. Approach to the patient with chronic diarrhea-I. In: Rose BD, editor. UpToDate (computer program), Wellesley MA: UpToDate; 2005. Available from: http://www.uptodate.com.

2. Talley NJ, O'Keefe EA, Zinsmeister AR, Melton LJ 3d. Prevalence of gastrointestinal symptoms in the elderly: a population based study. Gastroenterology 1992; 102:895.

3. Talley NJ, Zinsmeister AR, Van Dyke C, Melton LJ 3d. Epidemiology of colonic symptoms and the irritable bowel syndrome. Gastroenterology 1991; 101:927.

4. Sandler RS, Stewart WF, Liberman JN. Abdominal pain, bloating, and diarrhea in the United States: prevalence and impact. Dig Dis Sci 2000; 45:1166.

5. Everhart JE, editor. Digestive disease in the United States: epidemiology and impact. NIH Publ 94-1447. Bethesda: National Institutes of Health, 1994.

6. Ahlquist DA, Camiilleri M. Diarrhea and constipation In: Kasper DL, Braunwald E, Fauci AS, Hauser SL, Longo DL, Jameson JL et al. Harrison's Principles of Internal Medicine 16th ed. USA: McGraw-Hill, 2005: 224-232.
7. Al-Bayatti SM. Etiology of chronic diarrhea. Saudi Med J, 2002; 23: 675-9

8. Garg PK, Singh J, Dhali GK, Mathur M, Sharma MP Microscopic colitis is a cause of large bowel diarrhea in North India. J Clin Gastroenterol, 1996; 22: 11-5.

9. Hameed K, Khan I. Spectrum of ulcerative colitis in North-West Frontier Province of Pakistan. J Coll Physicians Surg Pak 2002; 12: 458-60.

10. Bhatti MA, Kashif MA, Imran M. Colonoscopic evaluation of middle aged patients with altered bowel habits. J Coll Physicians Surg Pak 2004;14: 4814.

11. Shah RJ, Fenoglio-Preiser C, Bleau BL, Gianella RA. Usefulness of colonoscopy with biopsy in the evaluation of chronic diarrhea. Am J Gastroenterol 2001; 96:1091-95.

12. Fine KD, Seidel RH, Do K. The prevalence, anatomic distribution and diagnosis of colonic causes of chronic diarrhea. Gastrointest Endosc 2000;51:318-26

13. Mullhaupt B, Guller U, Anabitarte M, Guller R, Fried M Lymphocytic colitis: clinical presentation and long term course. GUT 1998;43:629-33.

14. Sveinsson OA, Orvar KB, Birgisson S, Jonasson JG [Microscopic colitis-review.] Article in Icelandic. Laeknabladid 2008; 94:363-370.

15. Marshall JB, Singh $R$, Diaz-Arias AA. Chronic, unexplained diarrhea: are biopsies necessary if colonoscopy is normal? Am J Gastroenterol 1995; 90:372-6.

16. Lee JH, Rhee PL, Kim JJ, Koh KC, Paik SW, Han JH, Ree HJ, Rhee JC. The e role of mucosal biopsy in the diagnosis of chronic diarrhea: value of multiple biopsies when colonoscopic finding is normal or nonspecific. Korean J Intern Med 1997; 12:182-7.

17. Gineston JL, Sevestre H, Descombes P, Viot J, Sevenet F, Davion T, Dupas JL, Capron JP. [Biopsies of the endoscpically normal rectum and colon: a necessity, Incidence of collagen colitis and microscopic colitis]. Article in French. Gastroenterol Clin Biol 1989; 13:360-3. 
18. Thijs WJ, van Baarlen J, Kleibeuker JH, Kolkman J. Microscopic colitis: prevalence and distribution throughout the colon in patients with chronic diarrhea. Neth J Med 2005; 63:137-40.
AA, Sipahi AM, Histologic study of colonic mucosa in patients with chronic diarrhea and normal colonoscopic findings. J Clin Gastrenterol 2006; 40:44-8.

19. De Silva JG, De Brito T, Cintra Damiao AO, Laudanna

\section{HOUSE OFFIGERS REQUIRED}

$$
\text { at }
$$

INDEPENDENT UNIVERSITY WOSPITAL FAISALABAD

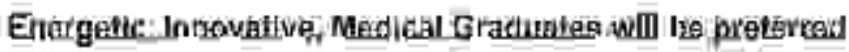

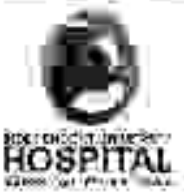

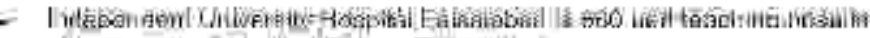

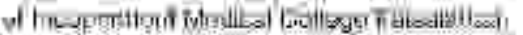

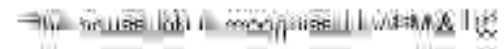

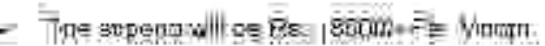

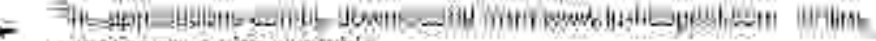

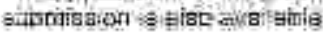
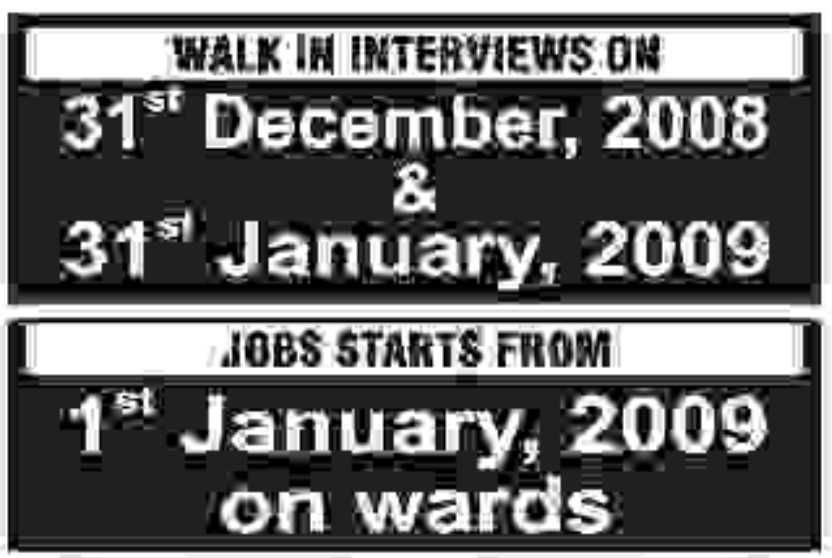

Mesilcal Superintendent

mojependenl teniversilx Hospital

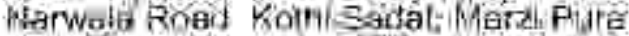

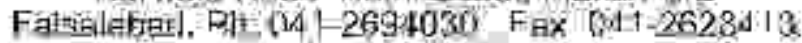

E-malt shujacahinchat-iospital com 